\title{
Pressure Transient Analysis of an Intersecting Rollover Faulted Crest Boundary in Niger Delta Oil Field
}

\author{
K. K. Ihekoronye, I. P. Nwosu \\ Petroleum Engineering, Federal University of Technology Owerri, Owerri, Nigeria \\ Email: kelechiking4@gmail.com, Nwosuip01@yahoo.co.uk
}

How to cite this paper: Ihekoronye, K.K. and Nwosu, I.P. (2019) Pressure Transient Analysis of an Intersecting Rollover Faulted Crest Boundary in Niger Delta Oil Field. Open Journal of Yangtze Gas and Oil, 4, 125-143.

https://doi.org/10.4236/ojogas.2019.42010

Received: February 8, 2019

Accepted: April 21, 2019

Published: April 24, 2019

Copyright $\odot 2019$ by author(s) and Scientific Research Publishing Inc. This work is licensed under the Creative Commons Attribution International License (CC BY 4.0).

http://creativecommons.org/licenses/by/4.0/

\begin{abstract}
Pressure transient analysis has been extensively applied to detect anomalies in a reservoir system. These anomalies may be presented in the form of an intersection of the crestal and the antithetic fault associated with a growth fault. Interpretation of this fault can only be achieved through the use of pressure transient analysis. The objective of the research work is to analyze and test the faulted crest, depth of the anticline structure and examine the near well bore conditions in order to evaluate whether the well productivity is governed by wellbore effects (skin effects + well bore effect) or the reservoir at large. A case study of a well in the Niger delta is considered with a series of build up test carried out in two intervals of both upper and lower gauge readings. In this study, a computer aided design which uses a pressure derivative approach is used in this work to match the pressure derivative of an intersecting fault (angle) model to the field data, and the model assumes the characteristics of the reservoir. Based on the result of the interpreted data, simulation is done by using a non linear regression method (least square). The simulated data interpreted are achieved through the regression coefficient which provides a quantitative measure of the agreement between field data and the model. In conclusion, the best cases are taken from all the results and a nodal analysis is performed to diagnose the inflow performance of the well through the transient analysis in order to optimize the recovery of the oilfield.
\end{abstract}

\section{Keywords}

Pressure Transient Analysis, Fault, Nodal Analysis, Wellbore Effect

\section{Introduction}

Many hydrocarbon bearing formations in the Niger Delta are faulted, as re- 
ported by [1], which contain rollover structure and intersected crest. However, [2] presents an analytical method to correct extrapolated static well pressures for a well in various drainage boundaries. [3] presents the concept of wellbore skin effect (factor). [4] in their work, it presents a work on pressure build up methods which agrees with the work by [5] which contains a log-log type curve for the wellbore-storage problem that starts the second era of well test analysis. [6] starts the first era of modern well test analysis: straight line methods. Semilog graphs of shut-in pressure vs. the logarithm of shut in time, to shut in time generates a straight line with reciprocal slope that is related to effective permeability Some faults are known to be sealing while others are non-sealing to the migration of hydrocarbon. Interpretation of this fault can only be achieved through the use of pressure transient analysis. [7] uses numerical well testing analysis to provide solution to non unique problems in heterogeneous reservoirs. In this study, a computer design that uses pressure derivative approach is used in this work to determine intersecting faults. Nodal analysis is also performed to determine the inflow performance of the well by help of transient analysis in order to optimize the recovery of the field. The objectives of the research work are as follows:

1) Test the faulted crest and depth of the anticline structure between the KRAKAMA east wells and the CAWTHORNE channel field.

2) Examine the near well bore conditions in order to evaluate whether the well productivity is governed by wellbore effects (skin + storage) or the reservoir at large.

3) Evaluate the well condition and reservoir characterization.

4) Provide an understanding of reservoir environment and the control which the geological architect exerts on fluid flow regimes and patterns.

5) Obtain the reservoir parameters for reservoir description such as reservoir conductivity $(\mathrm{KH})$, productivity index (PI), flow efficiency, damaged ratio, skin factor (S), average reservoir pressure.

6) Monitor changes in average reservoir pressure so that we can refine our forecast of future reservoir performance.

7) Give a comprehensive interpretation of the acquired data for efficient reservoir development and management decisions.

\section{Geology of the Reservoir}

The geology of the formation is shown in Figure 1 and Table 1 shows the reservoir and production data used for research analysis. The Well X28T is a vertical exploration well that was drilled in 1978 as Well Y-East-4. The X field well is drilled as an open hole to $10,445 \mathrm{ft}$ and intermediate logging runs and indicates $67 \mathrm{ft}$ net oil sand (NOS) and $20 \mathrm{ft}$ net gas sand (NGS) in 5 intervals between 7433 and 10,392 $\mathrm{ft}$. The open hole is plugged back and is sidetracked at $10,370 \mathrm{ft}$ to TD at $11,560 \mathrm{ft}$. During initial completion, it is found that the $95 / 8$ casing is damaged. It takes several re-entries before the casing is repaired. 


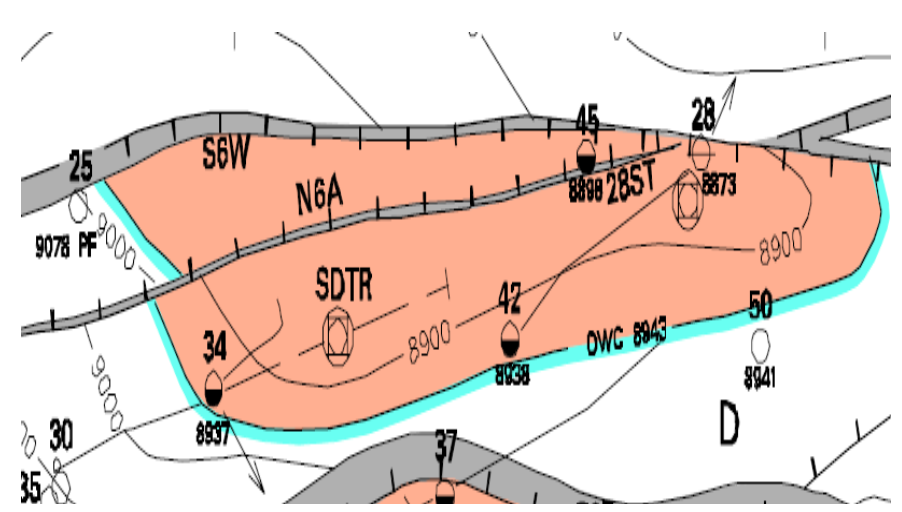

Figure 1. The Geology cross section map of Well 28T and it's boundaries.

Table 1. The reservoir and production data.

$\begin{array}{cr}\text { Reservoir and Fluid data } & \\ \text { Bubble point pressure } & 3883 \mathrm{psig} \\ \text { GOR } & 1032 \mathrm{scf} / \mathrm{stb} \\ \text { Oil FVF } & 1.46 \mathrm{rb} / \mathrm{stb} \\ \text { Reservoir temperature } & 172^{\circ} \mathrm{f} \\ \text { Reservoir pressure } & 4000 \mathrm{psia} \\ \text { Oil SG } & 0.8429 \\ \text { Gas SG } & 0.65 \\ \text { Net oil sand volume } & 0 \\ \text { Porosity } & 0.24 \\ \text { Connate water saturation } & 0.35 \\ \text { Average net thickness } & 130 \mathrm{ft} \\ \text { Wellbore radius } & 0.3 \mathrm{ft} \\ \text { Cumulative oil produced } & 202 \mathrm{stb} / \mathrm{day} \\ \text { Tested oil rate } & \\ \text { Production data } & 20 \\ \text { Choke size } & 20 / 64 \mathrm{in} \\ \text { Net oil rate } & 252.8 \mathrm{bbl} / \mathrm{day} \\ \text { Water cut } & 43.85 \\ \text { GLR } & 0.8 \\ \text { Wellhead pressure } & 29.9 \mathrm{BarG}\end{array}$

\section{Methodology}

\subsection{The Methodology Implores in This Work Is Outlined as Follows}

1) Reservoir data (well data, production history, pvt)

2) KAPPA (petroleum exploration software which covers the pressure transient analysis).

3) Emeraude (production logging interpretation tools)

4) Topaze (production analysis tools and used to know the productive depth level)

5) Saphir (well test interpretation package). 
The seismic study is carried out in the three wells to determine the level of faults boundary of the reservoir and the productive levels. This is done by using tool such as Topaze production tools.

\subsection{Emeraude Model Used for Analysis}

Figure 2 below shows the wellbore and skin of the intersected fault boundary of the homogenous reservoir used for research analysis.

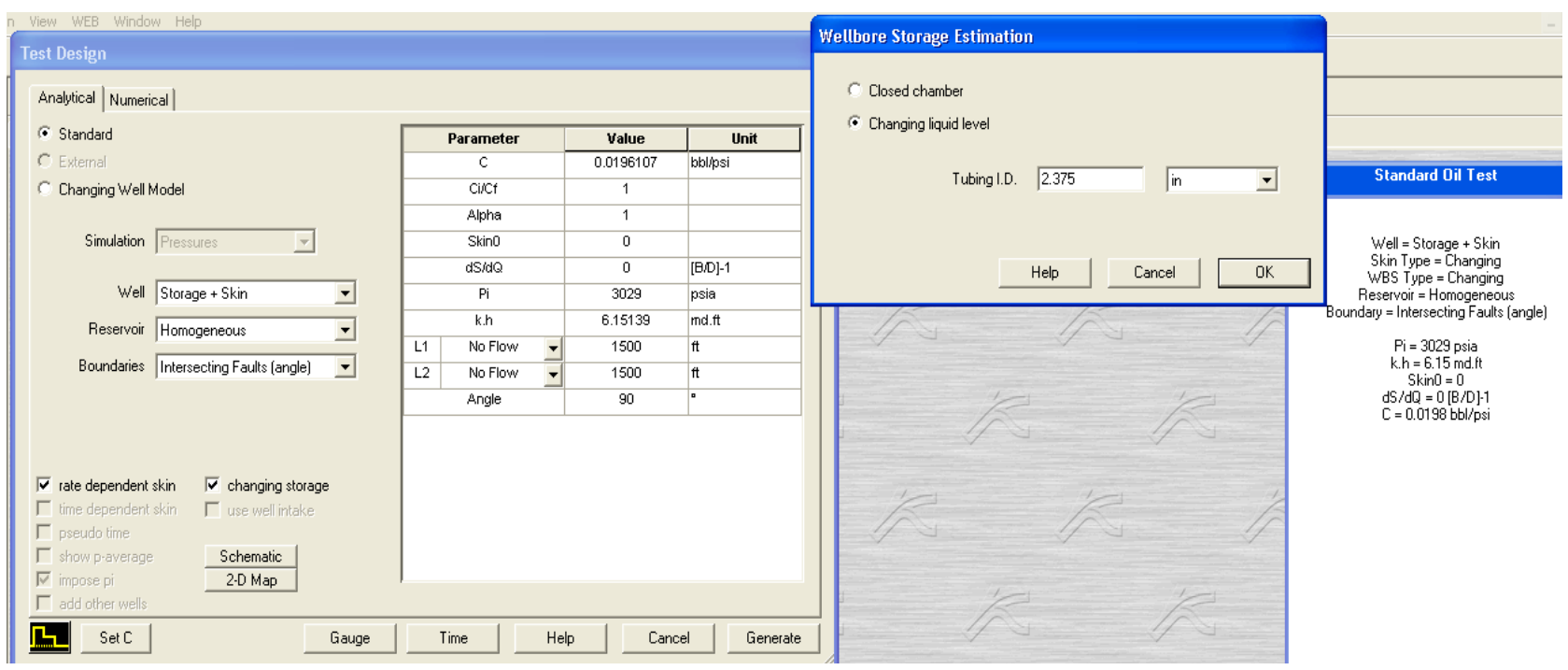

Figure 2. The model used for analysis.

\subsection{Parameter Estimation}

Once the reservoir model is identified, it is necessary to compute the model parameters. The parameters estimated from the specialized flow regimes analysis, interdisciplinary input or both resources, simulation for the transient responses are computed. The initial simulated and the observed response usually differs. Modern analysis however is assisted by the nonlinear regression routines that automatically refine the parameter estimates until the simulation coincides with the observed data for the essential portions of the transient response. Figure 3 and Table 2 show the parameter estimate for the confidence interval.

Table 2. The result summary used for the confidence limit correlation interval.

\begin{tabular}{cr}
\hline Parameter & Min - Max (Value) \\
\hline Confidence interval & $0.0197-0.0198(0.0197)$ \\
Correlation coefficient & $0.0391-0.157(0.0783)$ \\
Alpha & $0.316-0.752(0.438)$ \\
Skin & $0.0124-0.0284(0.0204)$ \\
$\mathrm{K}$ & $0.0473-0.0473(0.0473)$ \\
$\mathrm{L}_{1}$ (length) & $749-300(1500)$ \\
$\mathrm{L}_{2}$ (length) & $749-300(1500)$ \\
Angle & $44.929-179.716(89.858)$ \\
\hline
\end{tabular}




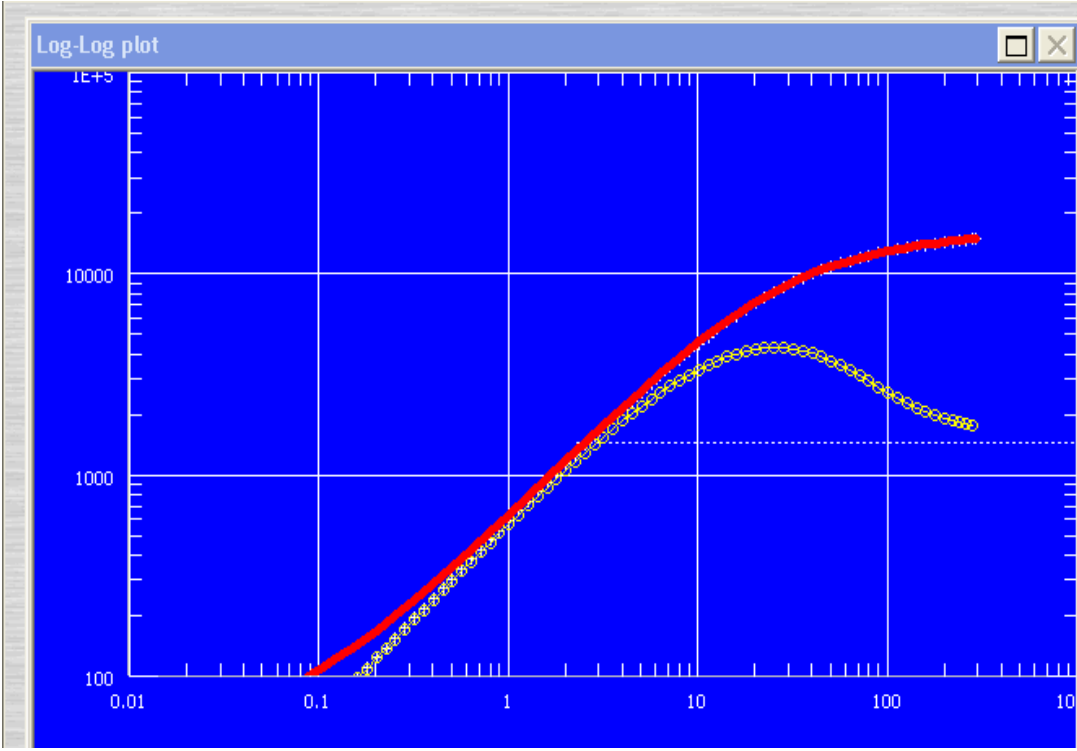

Confidence Limits

Figure 3. The parameter estimate and its confidence intervals.

\subsection{Model QA/QC}

The QA/QC control panels include all the facilities linked to well test data acquisition and quality control. The QA/QC section consists of series of plot of different types (pressure gauges, the difference of the plot, the linear derivative of the plot). Tide analyses are also performed on the pressure data to remove the effect of pressure measurement which heavily influences the derivative behavior and errors in the analysis are frequent induced. It is important to remove these effects without removing the true reservoir response before attempting and interpretation. This is done by using a smoothing of 0.1 to reduce the noise derivative as shows in Figure 4.

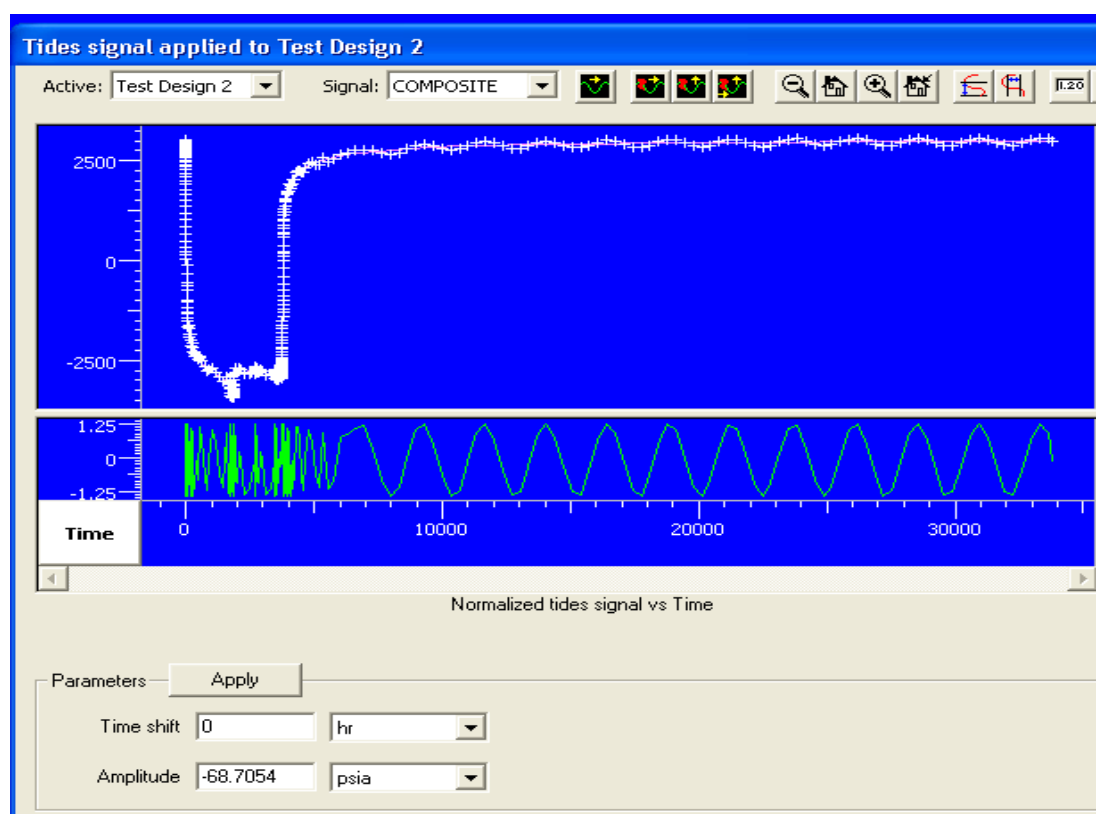

Figure 4. The tidal signal of the data used in the test design. 
The reservoir fluid properties are matched with PVT correlation in the model to calculate accurate viscosity and total compressibility of the fluid based on the assumed formation compressibility as shown in Figure 5.

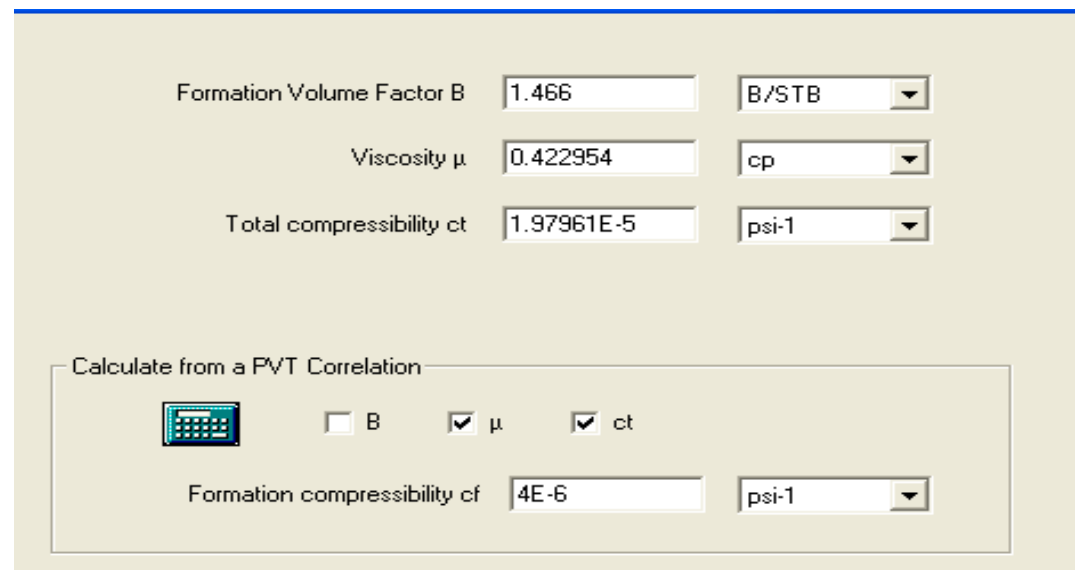

Figure 5. The match of PVT TEST result.

Permanent downhole gauges are used to record the bottom hole pressure and temperature with time. The upper and lower gauges of the downhole tool record the readings at both static and flowing conditions of the well. The static and flowing gradient reading are also recorded to determine slope of the fluid gradient for fluid contact. Comparing the conditions of the test for both upper and lower gauge responses, Kappa-saphir software is used in the diagnosis and further result and interpretation of the analysis are discussed as follows.

\section{Results Presentation}

Figure 6 shows the rate history of the test ranging from 400, 800 to 3200 is shown in the figure. However, Figure 7 and Figure 8 and Table 3 show the pressure derivative of the upper guage, Horner plot of the test and the result summary of the Horner plot are shown in Figure 8.

Figure 9 shows the semilog plot of the upper guage and Table 4 shows the result summary of the semillog test analysis as shown in the Figure 9.

Figures 10-12 show the gradient plot for the upper gauge, pressure derivative of the upper gauge and semilog of the lower gauge, whereas Table 5 shows the result summary of the semilog test analysis of the study.

Figures 13-15 show the Horner's plot of the lower gauge, pressure derivative of the lower gauge and semilog of the lower gauge used in the analysis. However, Tables 6-8 show the result summary of different test analyses of the Horner plot as shown in the figures.

Figures 16-18 show the Horner plot of the upper gauge, semilog of the lower gauge and comparison of the gauge result. Figure 19 shows the confidence limit of the values. While Table 9 and Table 10 show the result summary of the upper gauge and semilog of the lower gauge as shown in the figures.

Comparison of the gauge result 


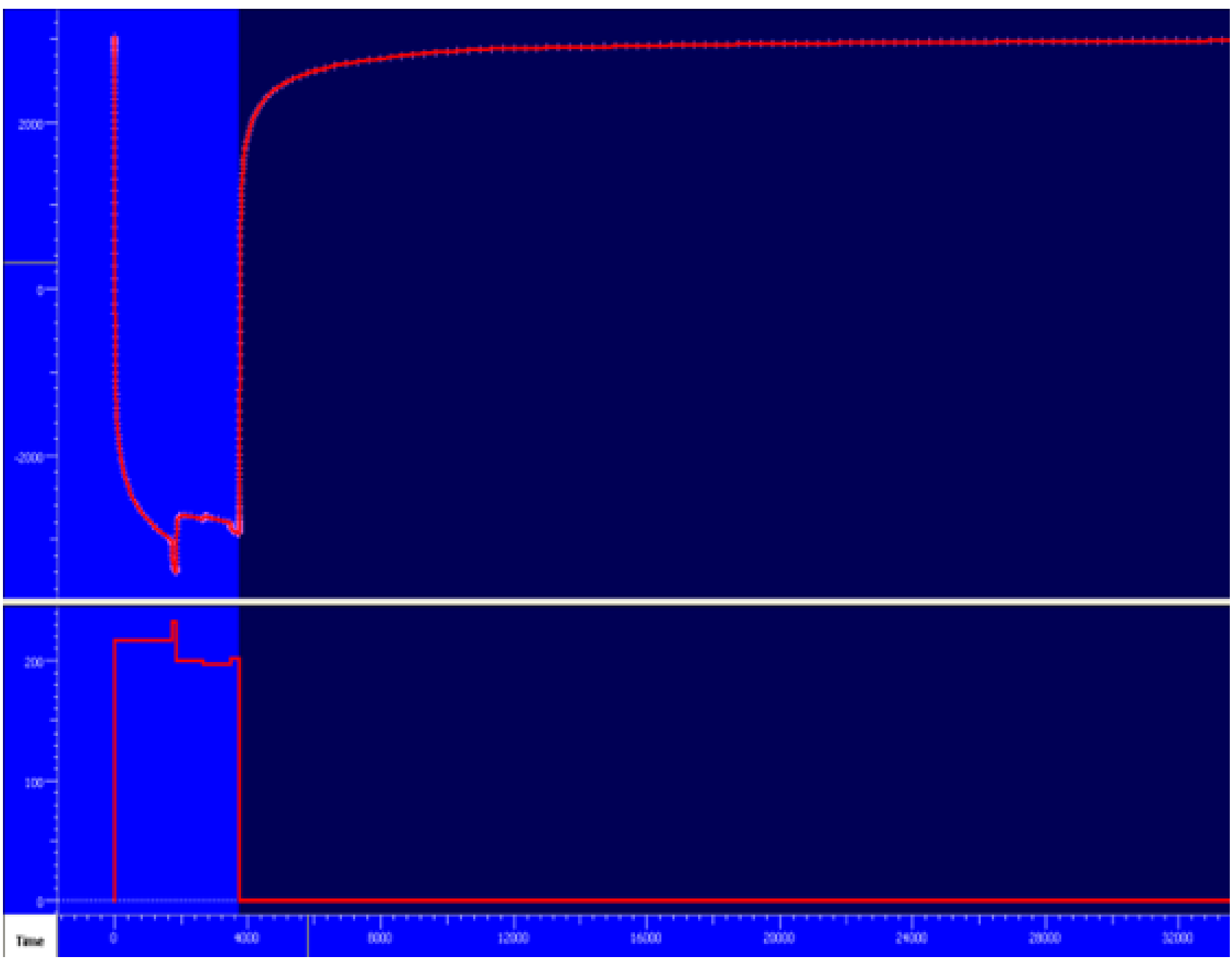

Figure 6. The rate history of the test design (ranging from 400, 800, 1200, 1400.. 3200).

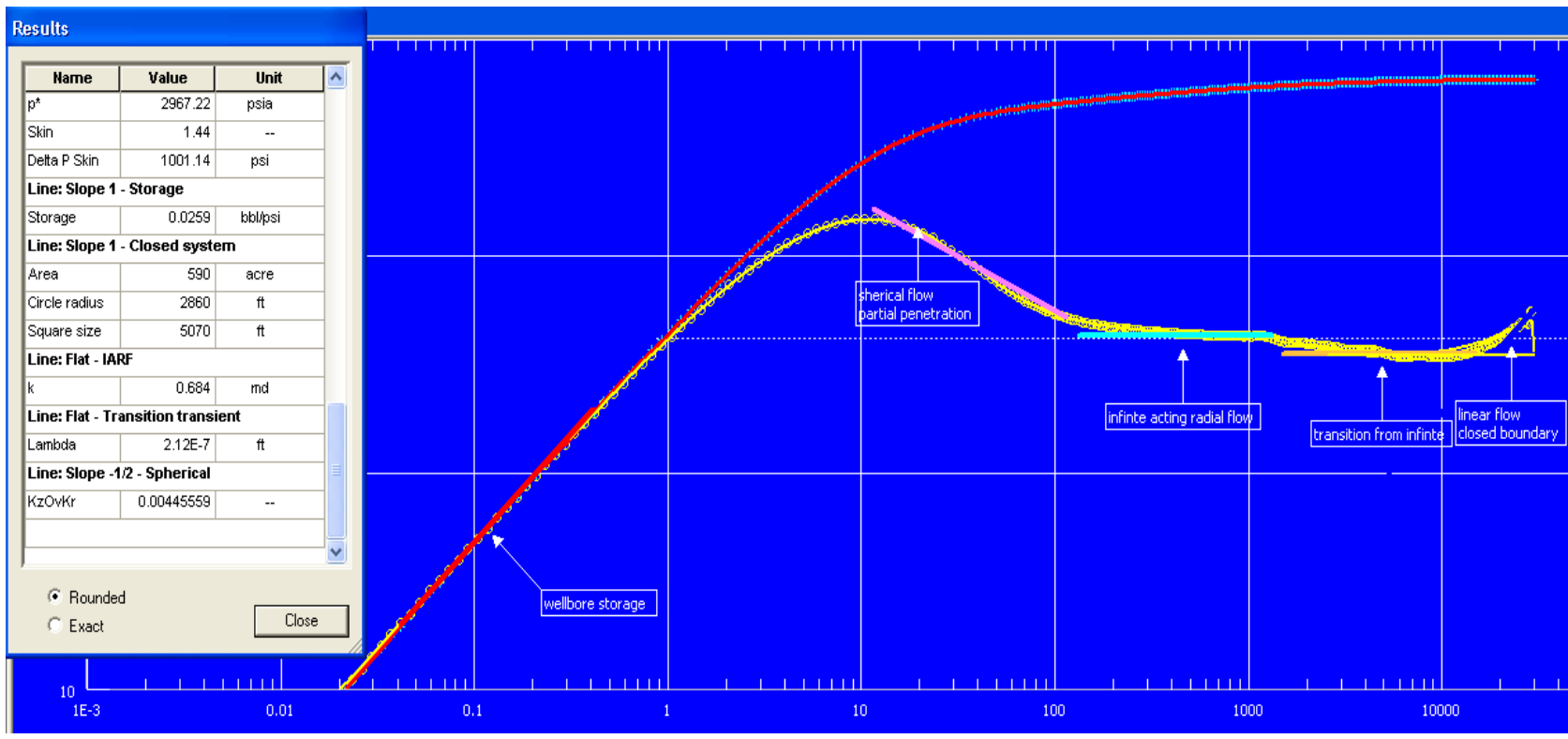

Figure 7. The pressure derivative for upper gauge (showing wellbore storage, spherical flow, infinite acting radial flow, transition flow to linear flow induced boundary). 


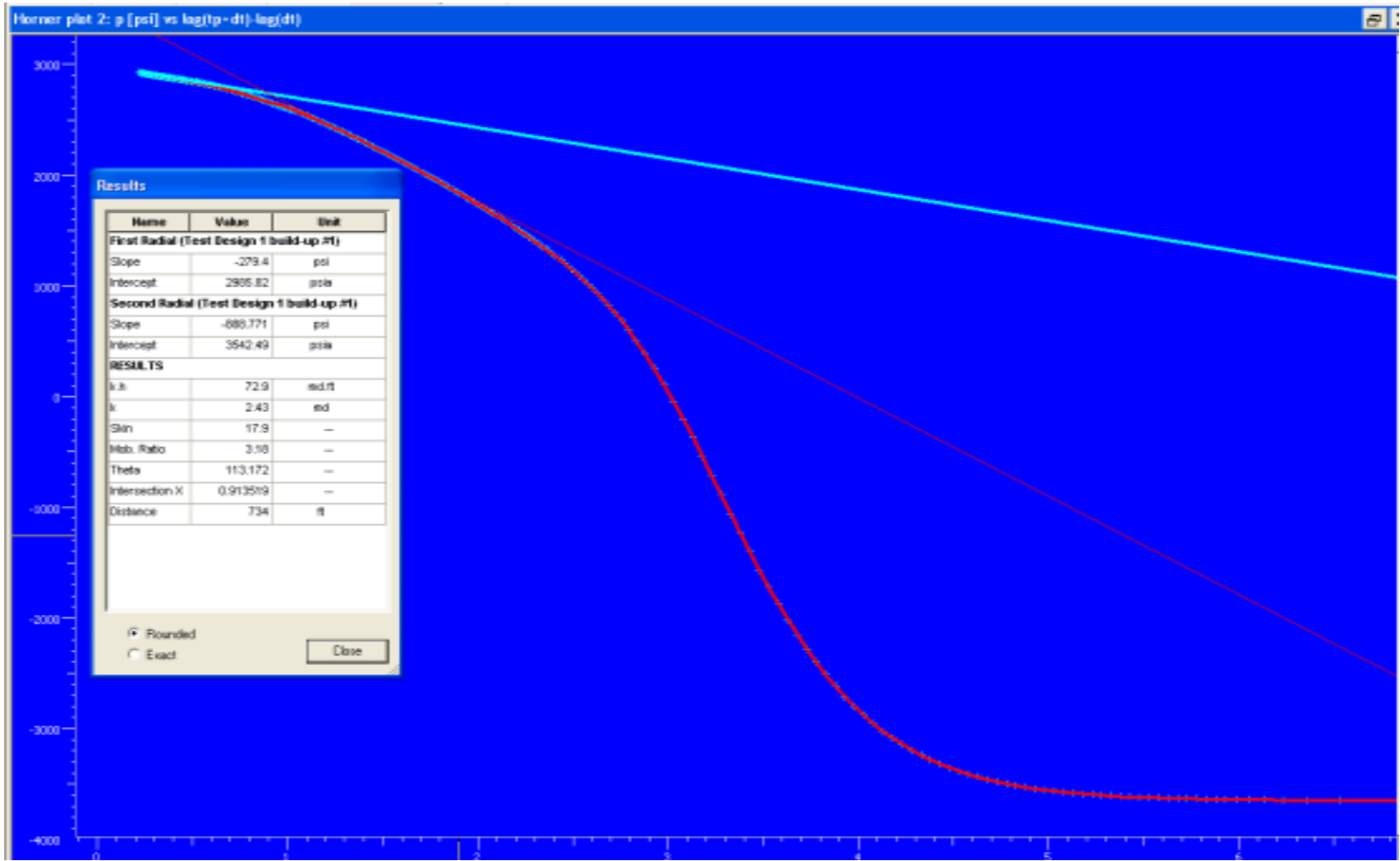

Figure 8. The Horner plot result of the test design.

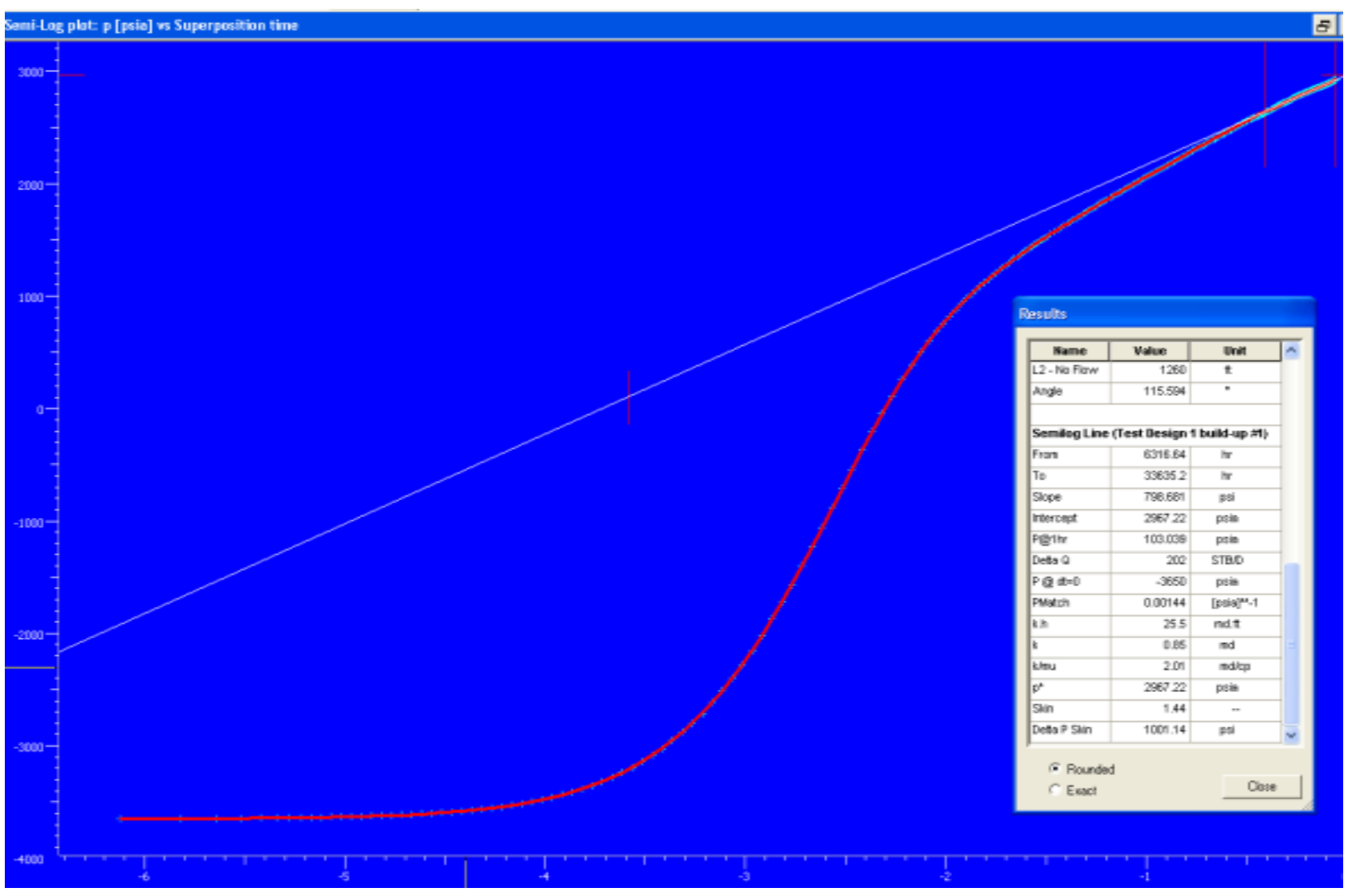

Figure 9. The semilog plot and its result for upper gauge. 


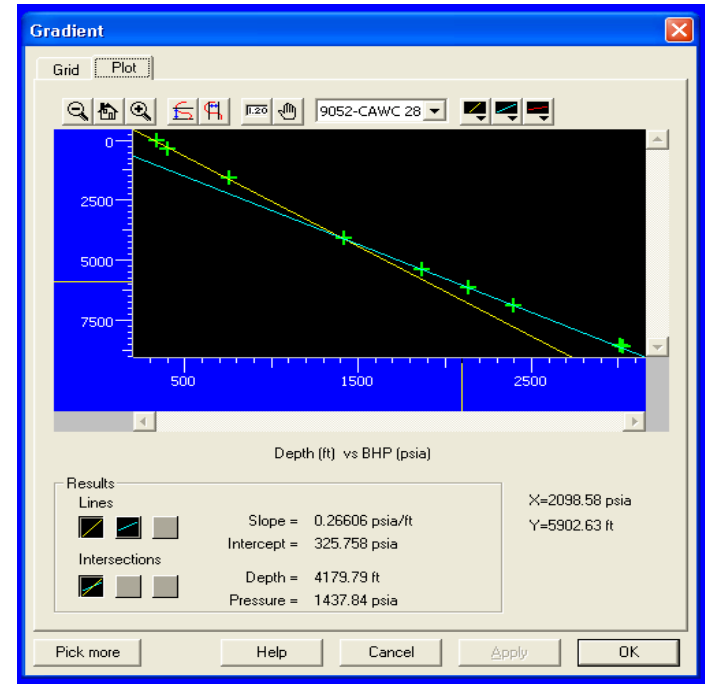

Figure 10. The gradient plot for upper gauge.

Table 3. The result summary from the Horner plot as shown in Figure 8.

\begin{tabular}{cc}
\hline & First radial test design build up \\
\hline Slope & $-293.4 \mathrm{mD}$ \\
intercept & $2906.82 \mathrm{Psia}$ \\
& second radial test design build up \\
Slope & $280.771 \mathrm{mD}$ \\
Intercept & $3542.49 \mathrm{Psia}$ \\
K (permeability) & $7.29 \mathrm{mD}$ \\
K (permeability) & $2.43 \mathrm{mD}$ \\
Skin & 17.9 \\
Net ratio & 3.98 \\
Intersection X & 0.9129 \\
Distance & 734 \\
\hline
\end{tabular}

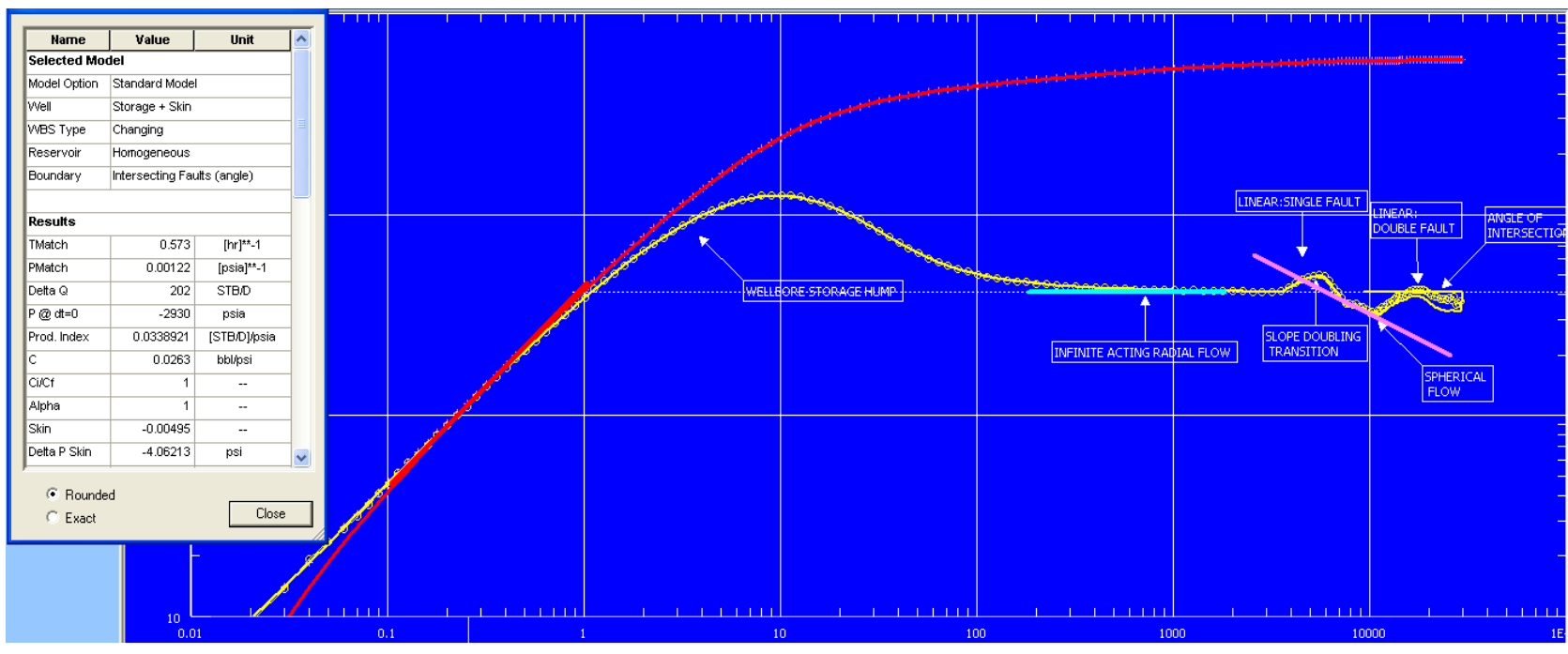

Figure 11. The Pressure derivative plot of the upper gauge (showing surface acting, infinite acting, spherical flow, linear flow). 


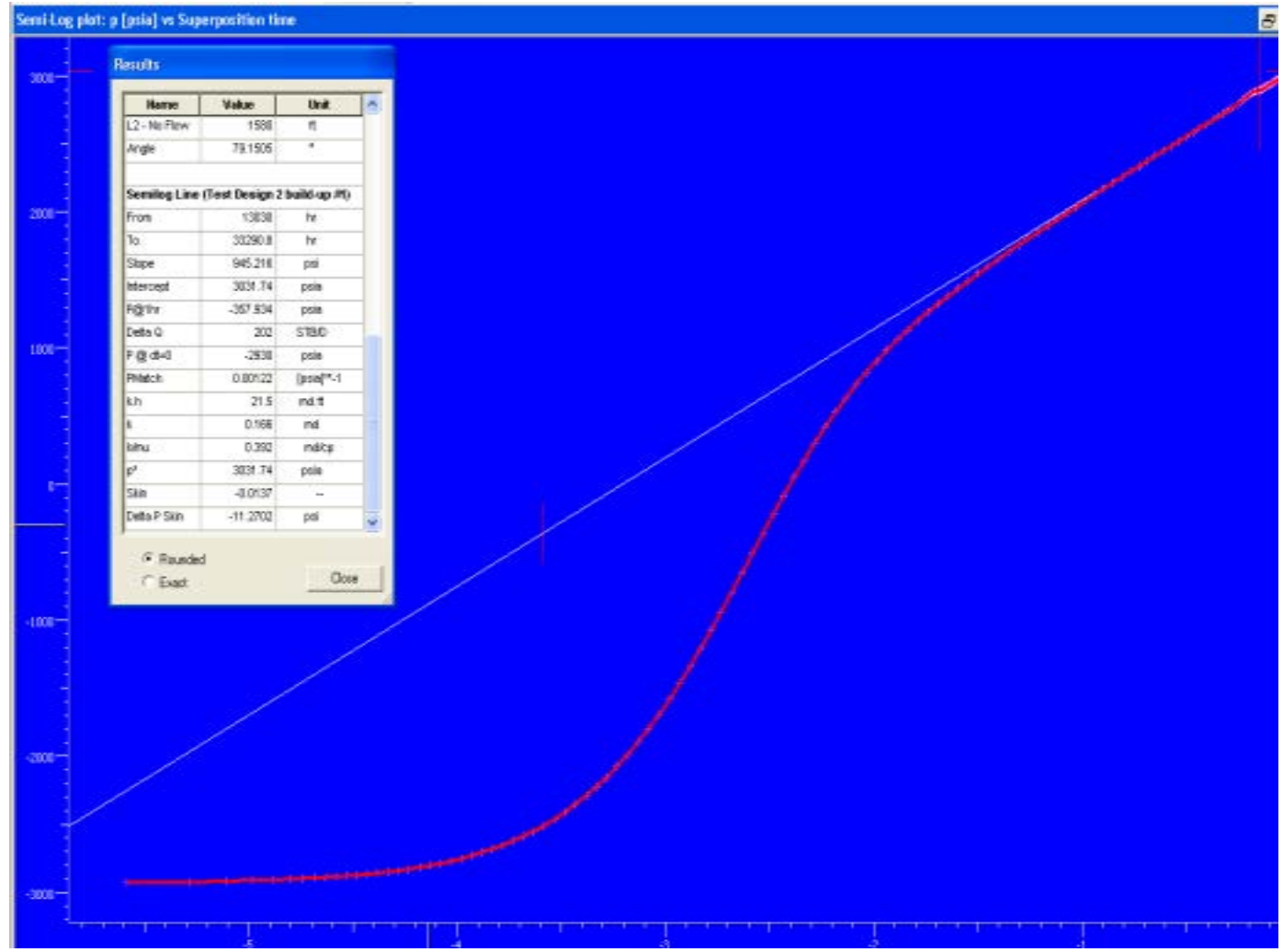

Figure 12. The Semilog for lower gauge.

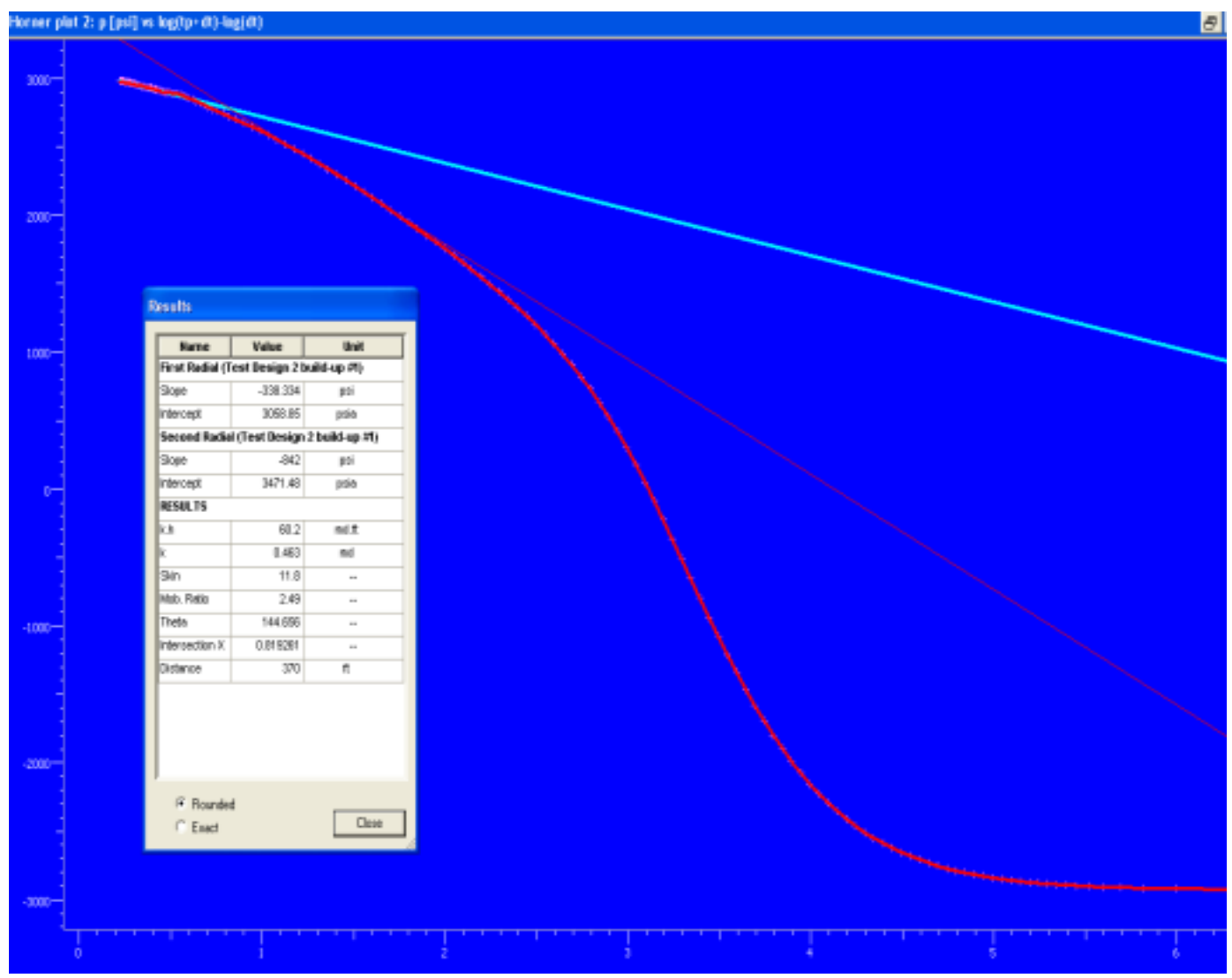

Figure 13. The Horner plot for the lower gauge. 
K. K. Ihekoronye, I. P. Nwosu

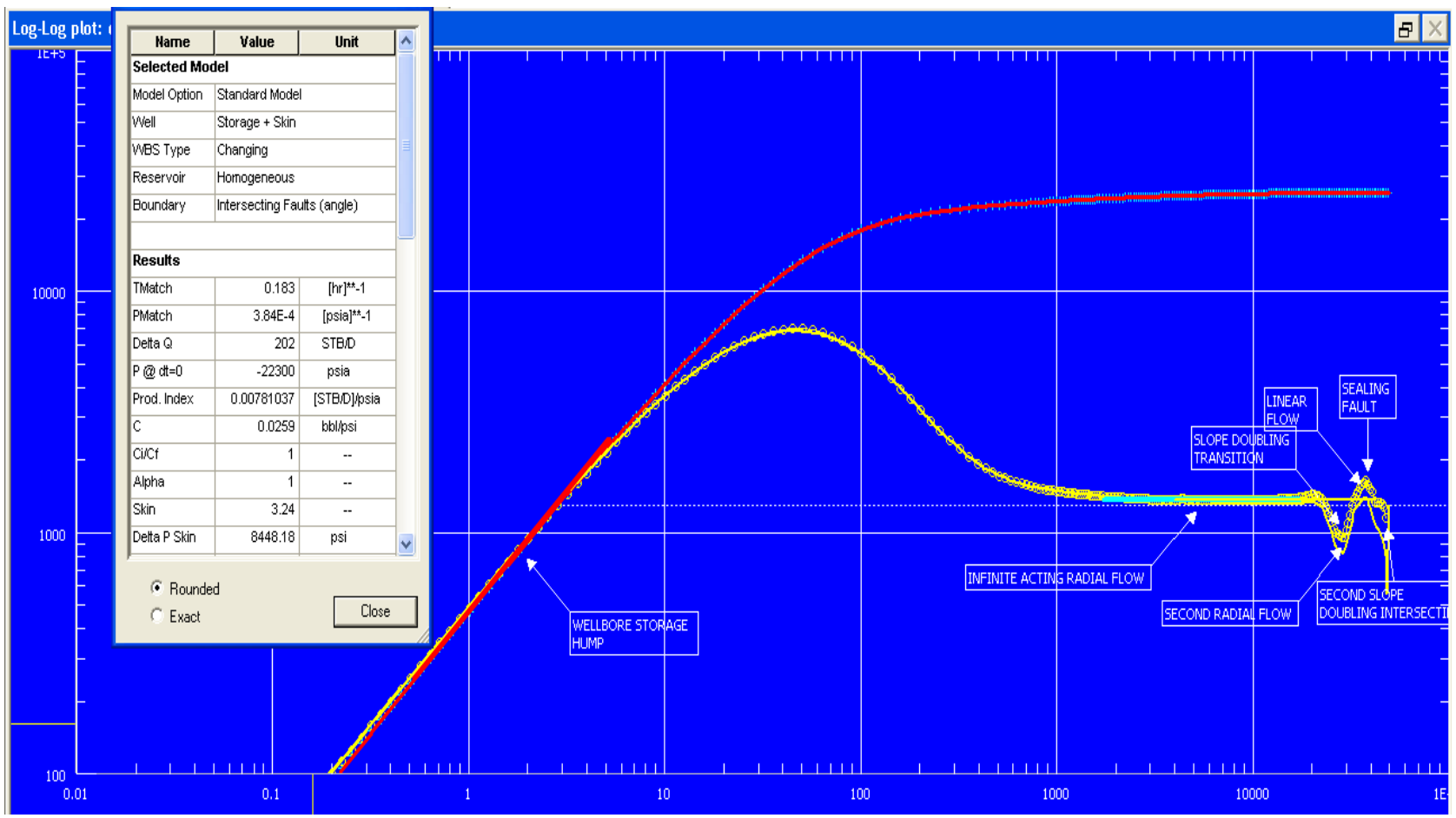

Figure 14. The pressure derivative plot of the lower gauge.

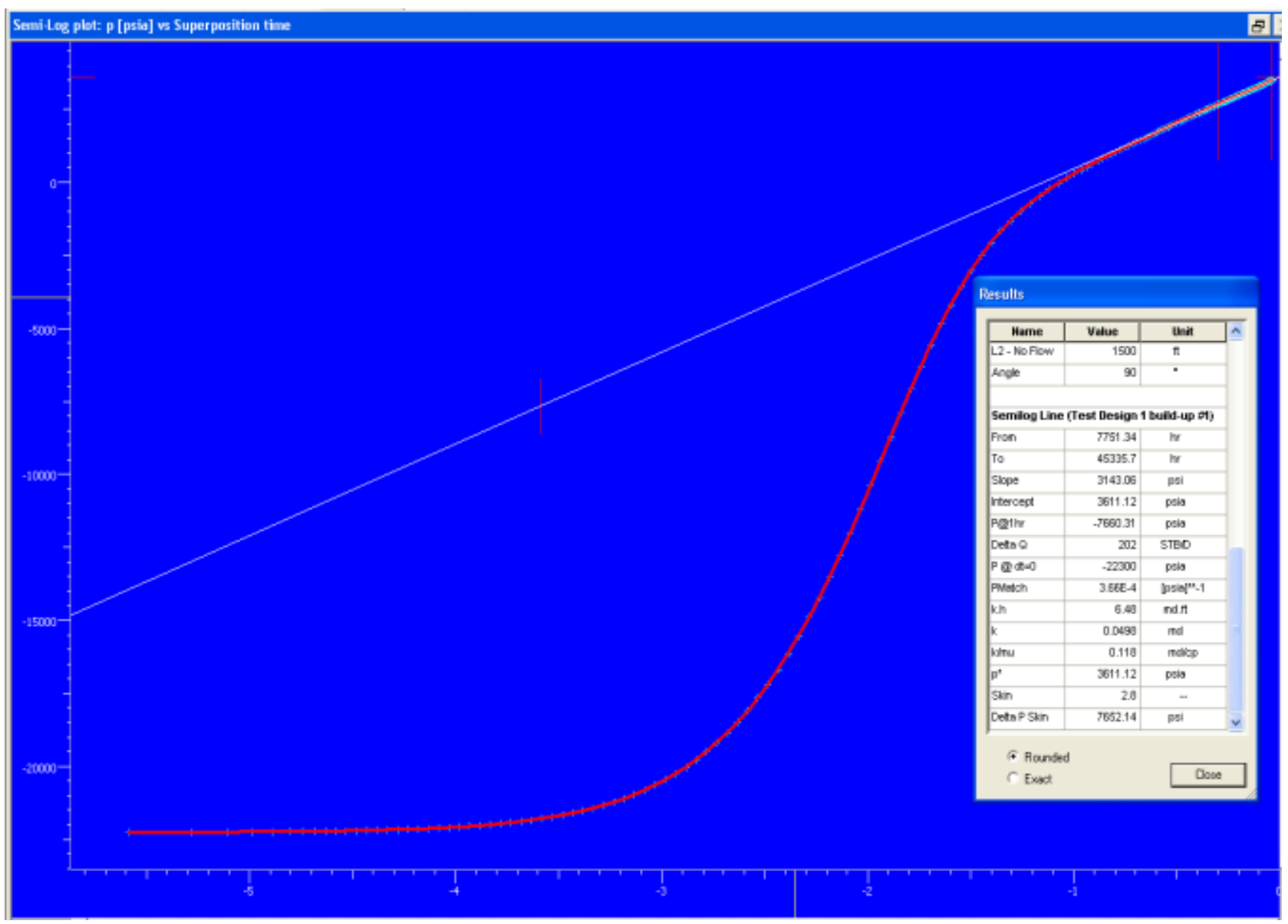

Figure 15. The semilog for upper gauge (SG). 


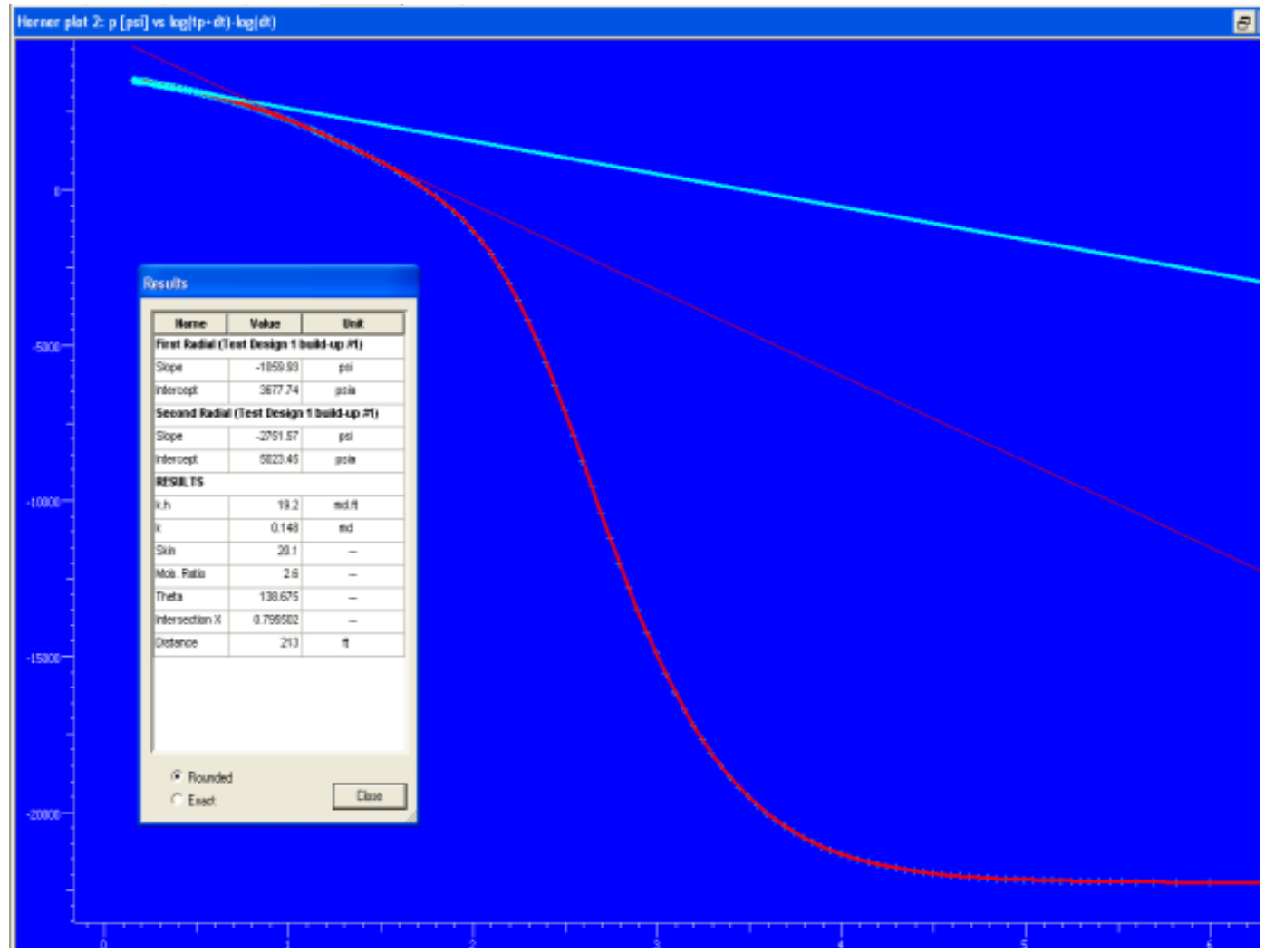

Figure 16. The Horner plot of the upper gauge.

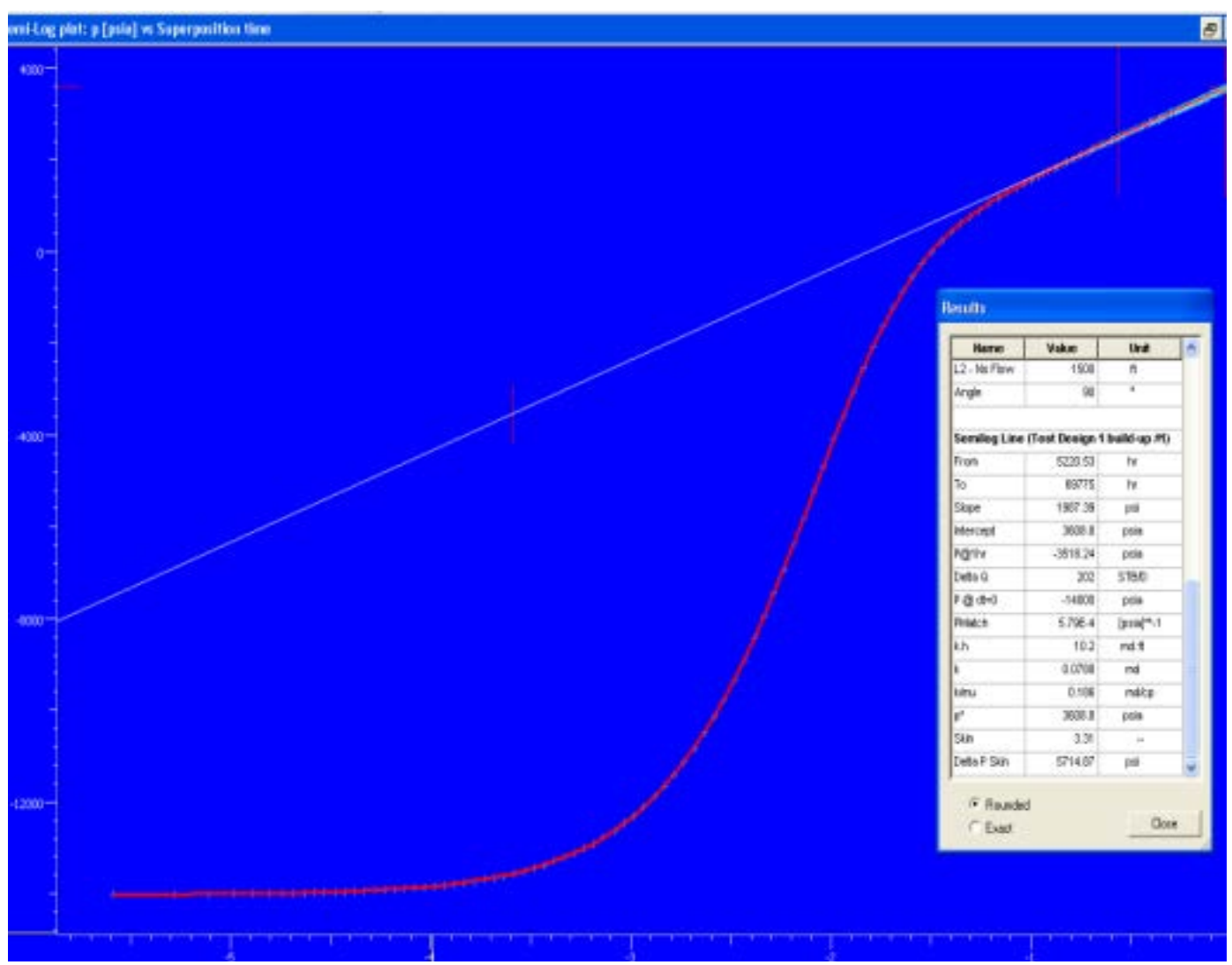

Figure 17. The result and the semilog plot of the lower gauge (SG) test design. 


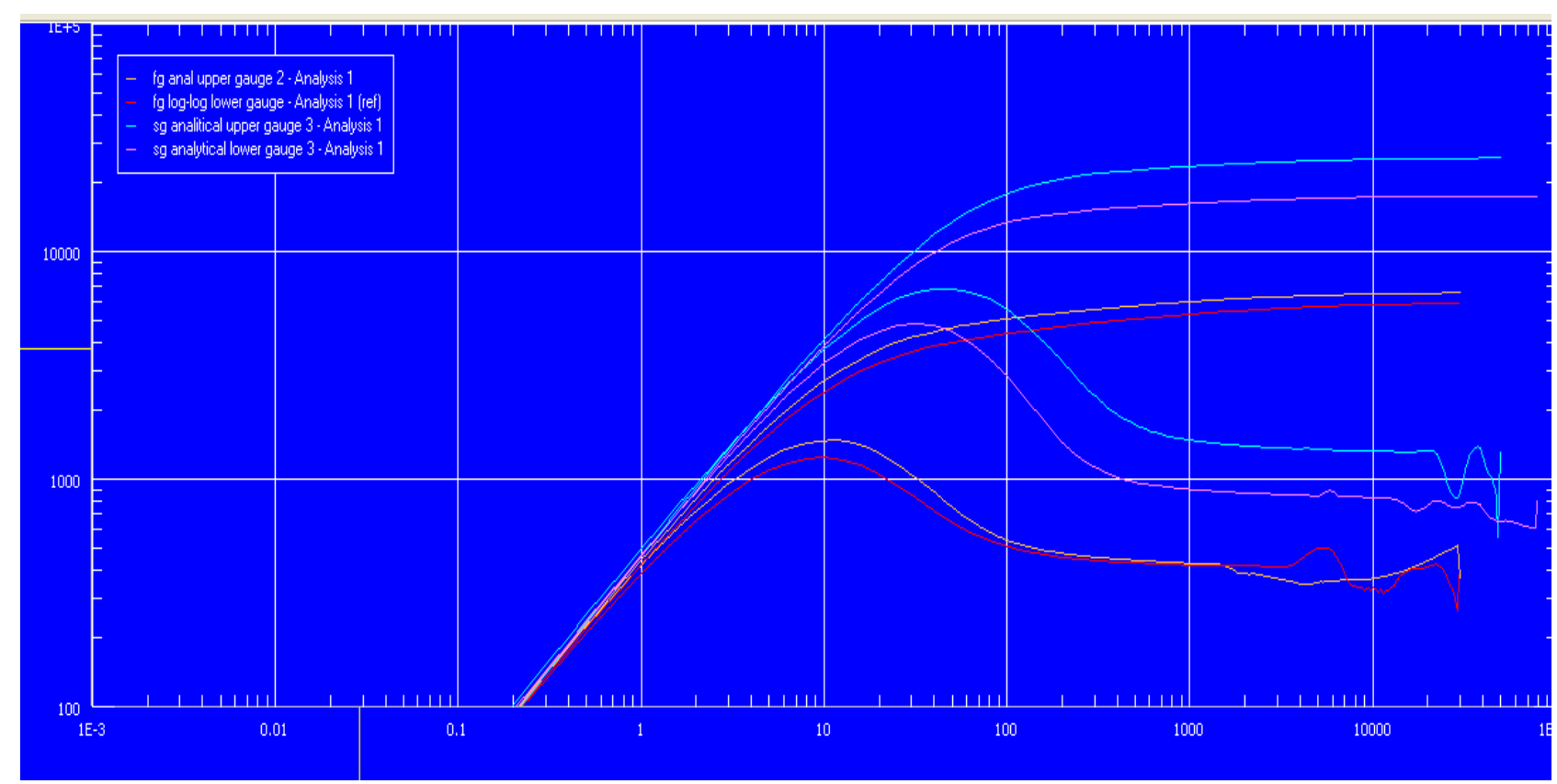

Figure 18. The gauge response with time.

\begin{tabular}{|c|c|c|c|}
\hline \multicolumn{4}{|l|}{ Confidence Limits } \\
\hline Confidence Intervals & \multicolumn{2}{|c|}{ Correlation Coefficients | } & \\
\hline Parameter & Minimum & Value & Maximum \\
\hline $\mathrm{c}$ & 0.0255 & 0.0257 & 0.0259 \\
\hline $\mathrm{Ci} / \mathrm{Cf}$ & 0.585 & 1.17 & 2.34 \\
\hline Alpha & 2.99 & 5.98 & 12 \\
\hline Skin & -0.0118 & 0.0143 & 0.0404 \\
\hline k & 0.703 & 0.706 & 0.708 \\
\hline L1 & 1620 & 1770 & 1920 \\
\hline L2 & 1210 & 1260 & 1320 \\
\hline Angle & 115.104 & 115.594 & 116.086 \\
\hline
\end{tabular}

Figure 19. The confidence limit of the upper gauge reading of the test simulation.

Table 4. The result summary for the semilog plot for upper guage as shown in Figure 9.

\begin{tabular}{cc}
\hline & Semi log line (Test Design build-up) \\
\hline Time from & $6314.54 \mathrm{~h}$ \\
To & $33635 \mathrm{~h}$ \\
intercept & 2967.22 Psia \\
P @1hr & 1000.009 Psia \\
Flowrate & 202 \\
Pressure (p@0) & 3650 Psia \\
Pws & 0.00564 Psia \\
Permeability (k) & $25.5 \mathrm{mD}$ \\
Skin & 1.44 \\
\hline
\end{tabular}


Table 5. The result summary of the semilog plot for lower guage as shown Figure 12.

\begin{tabular}{cc}
\hline & Semi log line (test design build-up) \\
\hline Time from & $138.90 \mathrm{~h}$ \\
To & $33290.1 \mathrm{~h}$ \\
Slope & $945.281 \mathrm{Psi}$ \\
intercept & $3031 \mathrm{Psia}$ \\
P @1hr & -361.834 Psia \\
Flowrate & $202 \mathrm{Stb} / \mathrm{d}$ \\
Pressure (p@0) & $2838 \mathrm{Psia}$ \\
Pws & $0.00564 \mathrm{Psia}$ \\
Permeability (k) & $0.168 \mathrm{mD}$ \\
Skin & 4.63 \\
\hline
\end{tabular}

Table 6. The result summary of the Horner plot for the lower guage as shown in Figure 13.

\begin{tabular}{cc}
\hline & First radial test design build up \\
\hline Slope & $338.354 \mathrm{mD}$ \\
Intercept & $3098.05 \mathrm{Psia}$ \\
& Second radial test design build up \\
Slope & $-945 \mathrm{mD}$ \\
Intercept & $3471.48 \mathrm{Psia}$ \\
Kh & $60.6 \mathrm{~m} / \mathrm{ft}$ \\
K (permeability) & $1463 \mathrm{Md}$ \\
Skin & 11.8 \\
Net ratio & 2.49 \\
Intersection X & 0.81831 \\
Distance & $370 \mathrm{ft}$ \\
\hline
\end{tabular}

Table 7. The result summary for pressure derivative of the lower guage as shown in Figure 14.

\begin{tabular}{cc}
\hline & Result \\
\hline Tmatch & $0.18300 \mathrm{~h}$ \\
Pmatch & $3.8 \times 10^{-4} \mathrm{psia}$ \\
Delta $\mathrm{p}$ & $202 \mathrm{Stb} / \mathrm{d}$ \\
p@d=0 & $-22,300 \mathrm{psia}$ \\
Production index & $0.00781037 \mathrm{Stb} / \mathrm{d}$ \\
compressibility & $0.02590 \mathrm{psi}$ \\
Alpha & 1 \\
Skin & 3.24 \\
Delta P skin & $8448.18 \mathrm{psi}$ \\
\hline
\end{tabular}


Table 8. The result summary of semilog for upper guage as shown in Figure 15.

\begin{tabular}{cc}
\hline & Semi log line (Test Design build-up) \\
\hline Time from & $7751.54 \mathrm{~h}$ \\
To & $4530.70 \mathrm{~h}$ \\
Slope & $3143.06 \mathrm{psi}$ \\
intercept & $3611.12 \mathrm{psia}$ \\
P @1hr & $-7660.31 \mathrm{psia}$ \\
flowrate & $202 \mathrm{Stb} / \mathrm{d}$ \\
Pressure (p@0) & $22,300 \mathrm{psia}$ \\
Kh & $6.43 \mathrm{mD} / \mathrm{ft}$ \\
Permeability (k) & $0.0493 \mathrm{mD}$ \\
Skin & 24 \\
\hline
\end{tabular}

Table 9. The result summary of the Horner plot of the upper guage as shown in Figure 16.

\begin{tabular}{cc}
\hline & First radial test design build up \\
\hline Slope & $-1059.19 \mathrm{mD}$ \\
Intercept & $3677.74 \mathrm{psia}$ \\
& Second radial test design build up \\
Slope & $-2759.17 \mathrm{mD}$ \\
Intercept & $5823.45 \mathrm{psia}$ \\
Kh & $19.2 \mathrm{~m} / \mathrm{ft}$ \\
K (permeability) & $0.148 \mathrm{mD}$ \\
Skin & 28.1 \\
Net ratio & 2.6 \\
Intersection X & 0.796582 \\
Distance & $281 \mathrm{ft}$ \\
\hline
\end{tabular}

Table 10. The result summary of the semilog plot of the lower guage test as shown in Figure 17.

\begin{tabular}{cc}
\hline & Semi log line (Test Design build-up) \\
\hline Time from & $5220.58 \mathrm{~h}$ \\
To & $6975 \mathrm{~h}$ \\
Slope & $1967.38 \mathrm{psi}$ \\
Intercept & $3608.1 \mathrm{psia}$ \\
\hline
\end{tabular}




\begin{tabular}{cc} 
Continued & \\
\hline P @1hr & $-2618.24 \mathrm{psia}$ \\
Flowrate & $202 \mathrm{Stb} / \mathrm{d}$ \\
Pressure (p@0) & $54800 \mathrm{psia}$ \\
Kh & $10.2 \mathrm{md} / \mathrm{ft}$ \\
Permeability (k) & $4.0708 \mathrm{mD}$ \\
Skin & 3.38 \\
\hline
\end{tabular}

\section{Discussion of Result}

Figure 1 shows the geology of the formation in the study, while Figures 2-5 show the model analysis used in the research work. Figures 6-8 show the producing response of the vertical well with wellbore storage and skin in a homogeneous reservoir of an intersecting fault with angle of intersection. The plot shows the $\log (\Delta \mathrm{p})$ derivative vs $\log (\Delta \mathrm{t})$ plot. The pressure derivative plot of the upper gauge reading shows the flow regimes of the fluid and their pressure responses with time. At first the well production is governed by the well bore storage followed by a transition into the transient state. The storage coefficient estimated from the derivative match is $0.0257 \mathrm{bbl} / \mathrm{psi}$ as a changing well bore storage which is proportional to pressure and assumed to estimate the skin factor which is used for the measurement of productivity of the well.

One of the main objectives of the research work is to estimate whether the productivity is governed by skin + storage, but as seen from the model result, the productivity is governed by skin + storage and its value predicting a low productivity index $0.03025 \mathrm{STB} / \mathrm{D}) / \mathrm{psi}$ with a skin effect of 0.014 . The result of the skin shows positive causing an increase in the pressure drop along the wellbore as shown in Figure 9 and Figure 10.

The second stage is the spherical flow regime which is attributed as a result of the effect of partial penetration of the fluid as fluid flows spherically from the formation into the wellbore before the top and bottom boundaries are reached. The reservoir thickness of the formation is calculated from the well-log survey as $130 \mathrm{ft}$ but only $20 \mathrm{ft}$ of the total formation is perforated. From the plot, the spherical flow (half slope) is used to calculate the ratio of vertical to radial permeability given as 0.00446 . The spherical flow lasts for about one cycle (10 - 100 hrs).

The third stage of the flow regime is the transient state (infinite acting radial flow). IARF is reached after the wellbore effect becomes negligible, the effect of well geometrics, the heterogeneities are passed and the lateral boundaries are detected. From the plot, the transient period begins at $100 \mathrm{hrs}$ and ends at 1000 hrs and the permeability estimated in this period is given as $0.684 \mathrm{md}$, which is a very low permeability. This period only lasts for a complete cycle before the transition of the transient into the pseudo steady state. This is due to the effect of the boundary as pressure drops with time are constant and the flow regime is li- 
near to the wellbore.

From the Horner plot shown in Figure 11, the first radial slope is more than double of the second radial flow which is due to the presence of faults.

Pressure derivative plot of the lower gauge reading shows the flow regimes of the fluid and their pressure response with time is shown in Figure 14. In this analysis, there are seven stages of the flow regime. At first the well production is governed by the well bore storage followed by a transition into the transient state. The storage coefficient estimated from the derivative match is $0.0263 \mathrm{bbl} / \mathrm{psi}$ as a changing well bore storage which is proportional to pressure assumed to estimate the skin factor for measuring the productivity of the well.

The productivity index is estimated at $0.034(\mathrm{STB} / \mathrm{D}) / \mathrm{psi}$ and a negative skin effect is also estimated (-0.00487), which indicates well improvement i.e. there is no pressure drop due to skin effect around the wellbore. The second stage of the flow regime is the transient state (infinite acting radial flow). From the plot in Figure 12, the transient period begins at $100 \mathrm{hrs}$ and ends at 10,000 hrs as long transient period is experienced during production. The effective permeability estimated in this period is given as $0.166 \mathrm{md}$, which is a very low permeability compared to the upper gauge. This period lasts for more than a complete cycle before the transition of the transient into the pseudo steady state. This is due to the effect of the boundary as pressure drops with time is constant and the flow regime is linear to the wellbore. Along a linear flow, a slope doubling transition can be seen, which indicates the presence of the first sealing fault forming a single trap in the formation.

The fifth flow regime is a spherical flow. This flow regime shows the effect of fluid flow due to the effect of the intersecting fault boundary cutting across an anticlinal structure. From the plot an estimate of the ratio of the vertical to radial permeability is done to account for the vertical flow across the barriers (boundaries), the estimated value is 0.075 . The sixth flow regime is the linear flow. The geometry of a linear flow streamline consists strictly of a parallel flow vectors. The presence of a second fault intersecting the sealing fault as seen in Figure 13 below shows the presence of the intersecting fault boundary and its effect to production as pressure changes with time is constant.

The seventh flow regime depicts the intersecting angle of the boundary. The Horner plot is used to validate the test model of the sand. From the Horner plot shown in Figures 15-17, the first radial slope is more than double of the second radial flow which is due to the presence of faults.

In Figure 18 and Figure 19, by comparing the two results with the effect of skin factor on the pressure response, the positive skin characterized from the upper gauge reading shows an effect on the pressure derivative curve by increasing the plot higher against the lower gauge response. The permeability response of the upper gauge is higher compared to the lower gauge from the infinite acting radial flow regime. In the same figure, comparing the pressure re- 
sponse of the upper and lower gauge of the second interval of the test design shows that the response of the infinite radial flow corresponds with each other but their flow responses due to the effect of the intersecting fault boundary are different.

\section{Conclusions}

Based on these results, a complete system analysis can be done to determine the optimum measure taken to optimize the total recovery of the reservoir sand and also help to determine the cost effectiveness of treatments under consideration and assists in completion decisions. This thorough evaluation of the complete producing system establishes the flow rate versus pressure drop relation for each component of the producing system. These could be as a result of the barriers from the interpretation of the gamma ray log of the formation as the matrix stimulation in 1995 was carried on the formation to improve its productivity and there was no positive result of improvement.

Barrier bar sands are deposited in a marginal marine environment on top of the finer grained barrier foot deposits. In a barrier bar, clay breaks are correlated over a long distance. The continuity of clay breaks or other barriers can be predicted from the depositional environment. The clay breaks may limit or stop the vertical flow of the fluids.

\section{Contribution to Knowledge}

A carefully study is needed for the behavior of reservoirs and establishing the fact that wellbore effect and skin contributes to low production of hydrocarbon as a result of intersecting fault boundary.

\section{Acknowledgements}

We thank the management of SPDC for giving me data to carry out the research.

\section{Conflicts of Interest}

The authors declare no conflicts of interest regarding the publication of this paper.

\section{References}

[1] Weber, K.J., Agarwal, R.G., Hussainy, R., Ramey Jr., H.J. and Daukoru, E.M. (1982) An Investigation of Welbore Storage and Skin Effect in Unsteady Liquid Flow. Transactions of AIME, 249.

[2] Matthews, C.S., Brons, F. and Hazebroek, P. (1953) A Method for Determination of Average Pressure in a Bounded Reservoir. Transactions of AIME, 201, 182-191.

[3] Matthews, C.S. and Russell, D.G. (1967) Pressure Buildup and Flow Test in Well, Monograph Series. SPE, Richardson.

[4] Van Everdingen, A.F. and Hurst, W. (1949) Application of the Laplace Transforma- 
tion to Flow Problem in Reservoirs. Transactions of AIME, 305-324.

[5] Van Everdingen, A.F. (1953) The Skin Effect and Its Influence in the Productive Capacity of a Well. Transactions of AIME, 198, 171-176. https://doi.org/10.2118/203-G

[6] Horner, D.R. (1950) Pressure Build-Up in Wells. In: Brill, E.J., Ed., Proceedings of the Third World Pet. Cong., Leiden II, 503-522.

[7] Zheng, P., Rosa, A.J. and Horne, R.N. (2006) Automated Type-Curve Matching in Well Test Analysis Using Laplace Space Determination of Parameter Gradients. SPE Annual Technical Conference and Exhibition, San Francisco, 5-8 October 2006.

Submit or recommend next manuscript to SCIRP and we will provide best service for you:

Accepting pre-submission inquiries through Email, Facebook, LinkedIn, Twitter, etc. A wide selection of journals (inclusive of 9 subjects, more than 200 journals)

Providing 24-hour high-quality service

User-friendly online submission system

Fair and swift peer-review system

Efficient typesetting and proofreading procedure

Display of the result of downloads and visits, as well as the number of cited articles

Maximum dissemination of your research work

Submit your manuscript at: http://papersubmission.scirp.org/

Or contact ojogas@scirp.org 